\title{
Do we care about people with chronic pain?
}

\author{
Mary E Lynch MD FRCPC
}

$T^{1}$ he Canadian Medical Association and other members of the Canadian Wait Time Alliance have identified national benchmarks for the management of pain. They recommend maximum wait times of six months for adults with chronic pain and shorter benchmarks for specific types of pain that are potentially reversible if treated early (1). Unfortunately, we are not achieving these objectives. A national survey (2) indicated that wait times for treatment at publicly funded pain clinics across Canada substantially exceeded these benchmarks. Wait times exceeded one year at over $30 \%$ of the clinics surveyed and ranged up to five years in some settings, with large areas of Canada having no service whatsoever. We know that this means both unacceptable levels of suffering and large numbers of people whose conditions deteriorate while waiting for access to care. This deterioration includes increased pain and decreased health-related quality of life, as well as escalating depression (3). In addition to human suffering, chronic pain is associated with a significant economic burden in terms of direct health care costs and indirect costs related to disability caused by pain. It is critical to address the needs of this population, but the challenges are significant.

In the paper titled "The need for knowledge translation in chronic pain" in the present issue of Pain Research Eु Management (4), Henry emphasizes the need for a paradigm shift, pointing out that the acute care model that dominates in most areas of medicine cannot meet the growing need to address chronic conditions. He argues persuasively that a chronic disease management model is the direction we must take. Henry quotes EH Wagner, author of the United States National Coalition on Health Care Report, who concludes that significant and effective advances in the management of chronic illnesses have led to major reductions in suffering and complications; however, only a minority of people with these chronic conditions receive appropriate treatment. He points out that "especially lacking is support for patients' efforts to manage their own health".

Canadian researchers have taken a leading role in applying self-management principles to the control of chronic pain
$(5,6)$. Several initiatives, both regional (Calgary Health Region) and provincial (Nova Scotia, British Columbia and Quebec), have succeeded in taking initial steps toward building capacity using this model. To support and facilitate these initiatives, the Canadian Pain Society has launched a National Task Force on Service Delivery. These are laudable initiatives, but they will only be successful on a national level if we adopt the approach presented by Henry - namely, systemwide strategic action. The critical challenge we all face is to change the mindset of the general public, health care practitioners, politicians and policy makers so that they convert from seeing pain as a simple symptom and blaming patients when they develop chronic pain, to understanding chronic pain as a disease in its own right. Furthermore, it must be appreciated that chronic pain inflicts a heavy burden on Canadians and the Canadian economy. We urgently need to take serious action to address this escalating public health care challenge. Henry has presented it all here in one place the evidence is strong and clear; a clarion call has been raised. This is not just an excellent topical review. It is a manifesto and we should adopt it.

\section{REFERENCES}

1. Alliance WT. Time for Progress: 2007.

$<$ http://www.waittimealliance.ca> (Version current at June 27, 2008).

2. Peng P, Chouiniere M, Dion D, et al; STOPPAIN Investigators Group. Challenges in accessing multidisciplinary pain treatment facilities in Canada. Can J Anesth 2007;54:977-84.

3. Lynch ME, Campbell FA, Clark AJ, et al. A systematic review of the effect of waiting for treatment for chronic pain. Pain 2008;136:97-116.

4. Henry JL. The need for knowledge translation in chronic pain. Pain Res Manage 2008;13:465-476.

5. LeFort SM, Gray-Donald K, Rowat KM, Jeans ME. Randomized controlled trial of a community-based psychoeducation program for the self management of chronic pain. Pain 1998;74:297-306.

6. McGillion MH, Watt-Watson J, Stevens B, Lefort SM, Coyte P, Graham A. A psychoeducation trial for self management of chronic cardiac pain. J Pain Symptom Manage 2008;36:126-40. 


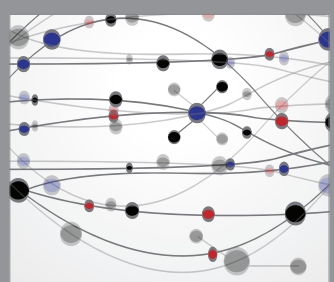

The Scientific World Journal
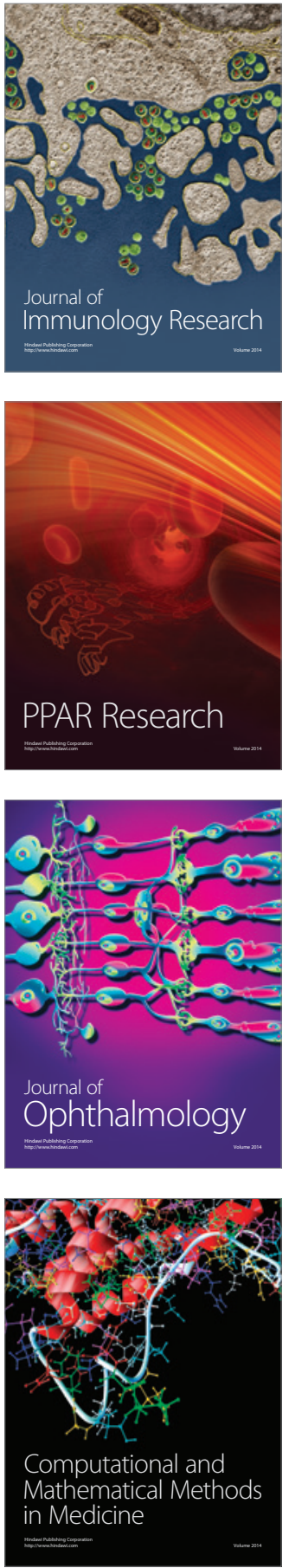

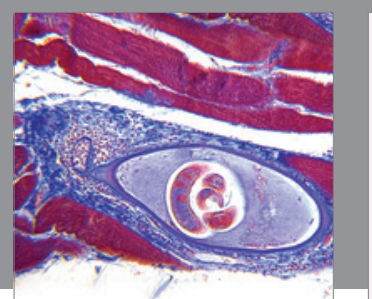

Gastroenterology Research and Practice

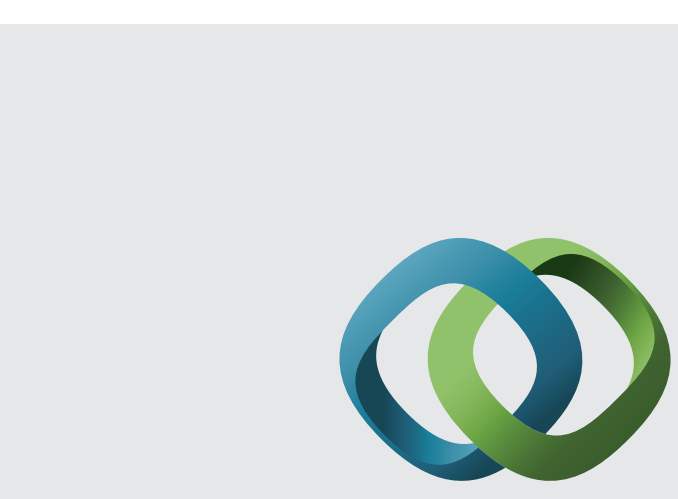

\section{Hindawi}

Submit your manuscripts at

http://www.hindawi.com
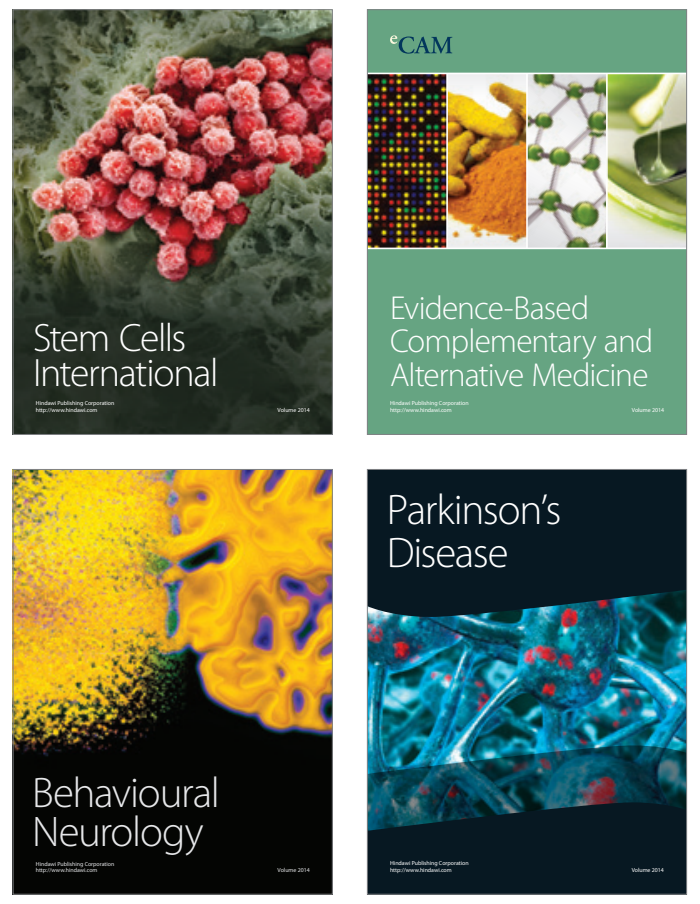
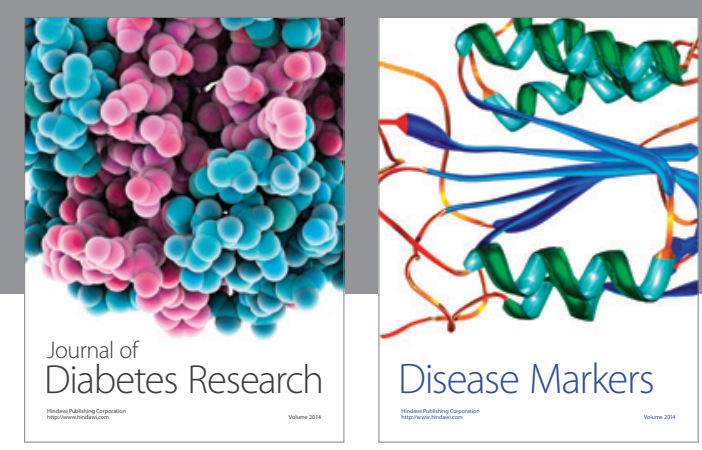

Disease Markers
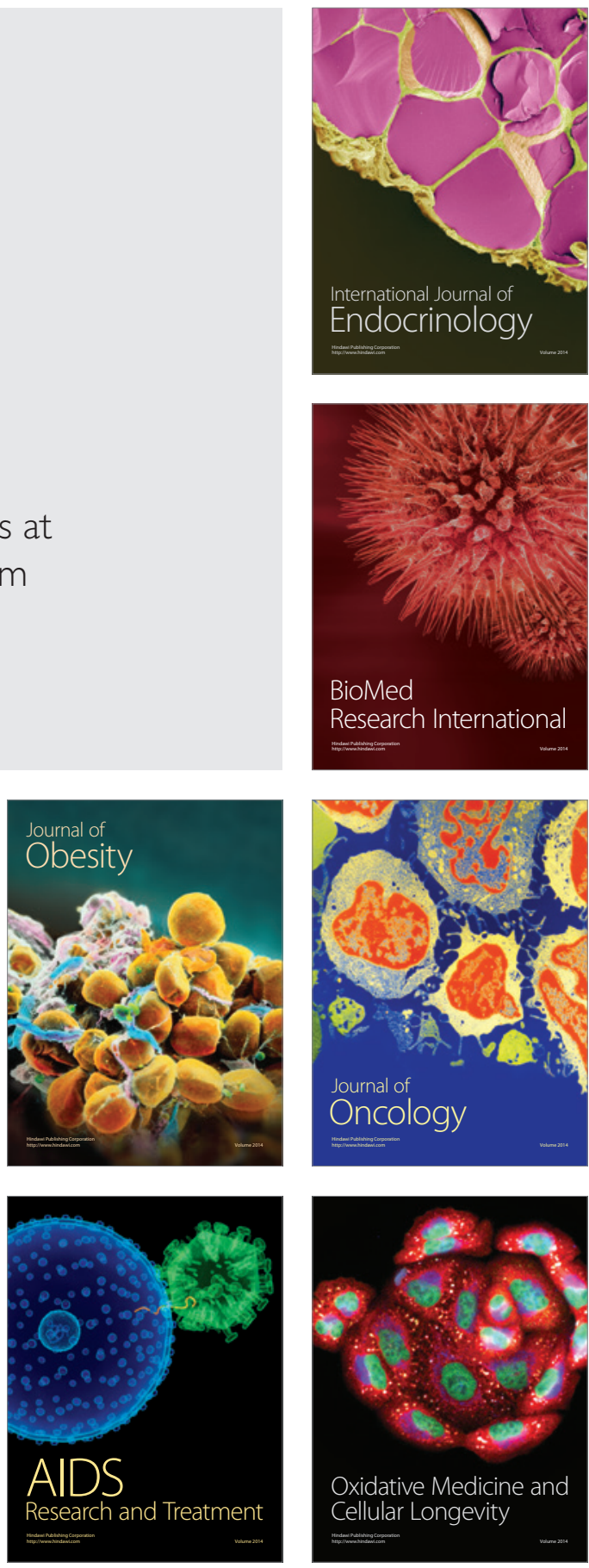